\title{
A concept for disposal of highly acidic spent nuclear fuel solutions at PSI
}

\author{
Mu Lin ${ }^{1,2} \cdot$ Ivan Kajan $^{1} \cdot$ Dorothea Schumann $^{1}$ (D) Andreas Türler ${ }^{2}$
}

Received: 23 July 2019 / Published online: 15 October 2019

(c) The Author(s) 2019

\begin{abstract}
During previous radioanalytical studies at Paul Scherrer Institute ca. $30 \mathrm{~L}$ of acidic waste containing spent nuclear fuel was produced, and now they need to be disposed A flow sheet for conditioning of these waste was designed and the extraction chromatography technique is evaluated. Suitable sorbents, such as AMP_PAN, TBP impregnated resin and DGA resin, were selected for the task of Cs-removal, extraction of $\mathrm{U}$ and $\mathrm{Pu}$, and extraction of minor actinides and lanthanides, respectively. A pilot device will be built for preliminary tests with simulated solutions, and the facility will be built and evaluated with the real spent fuel solutions.
\end{abstract}

Keywords Extraction chromatography $\cdot$ Spent nuclear fuel $\cdot$ Ion exchange $\cdot$ Cesium $\cdot$ Lanthanides $\cdot$ Actinides

\section{Introduction}

Radioanalysis of spent fuel pellets is important for nuclear power plants, both, concerning the management of the fuel cycle and waste disposal. Several decades ago, a number of radioanalytical studies on ca. $700 \mathrm{~g}$ of spent nuclear fuel samples from Swiss nuclear power plants were performed at Hot Laboratory (hotlab), Paul Scherrer Institute (PSI), Switzerland. The samples were dissolved in approximately $30 \mathrm{~L}$ of 8-10 $\mathrm{M} \mathrm{HNO}_{3}$ and the remaining solutions have been stored at hotlab for several decades and now they need to be properly disposed. In Switzerland, deep geological storage is adopted as the disposal concept for radioactive waste [1]. Based on this, these spent fuel solutions have to be cemented for geological storage.

\section{Concept of the "Fixbox" conditioning}

A facility for conditioning of liquid radioactive waste, the so-called Fixbox 3 [2], was developed at PSI. This facility was installed in glove-boxes and gamma-shielded for

Dorothea Schumann

dorothea.schumann@psi.ch

1 Laboratory of Radiochemistry, Paul Scherrer Institute, Forschungsstrasse 111, 5232 Villigen, Switzerland

2 Department of Chemistry and Biochemistry, University of Bern, Hochschulstrasse 4, 3012 Bern, Switzerland handling the waste containing alpha- and gamma emitters, respectively. The Fixbox 3 procedure consists of chemical conditioning and pre-cementation. Acids are foreseen to be neutralized by standard solutions in the chemical conditioning step and several packages of $1 \mathrm{~L}$ can be produced in the pre-cementation step. Finally, these packages are solidified with cement in an approximately $200 \mathrm{~L}$ metal drum before being transferred to the geological storing site. In order to fulfill the requirements of the Fixbox 3 procedure, the gamma dose rate, mainly stemming from ${ }^{137} \mathrm{Cs}$ (halflife: $\sim 30$ a) [3], must be significantly reduced.

\section{Isotope reclamation}

Samples or solutions of spent nuclear fuel do not only impose huge efforts for conditioning and disposal, but contain also valuable materials for scientific studies i.e. for neutron induced fission- and capture cross sections, which are urgently needed and can hardly be obtained by other means. In the following paragraph, we explain these "spinoff" applications in more detail:

To optimize the design of advanced nuclear energy systems, and especially systems aimed to "burn" spent nuclear fuel, accurate nuclear reaction data for a large number of isotopes are required. In particular, high-accuracy, high-resolution cross-section data are needed on neutron induced reactions (capture, fission and inelastic reaction) 
for several actinides, long-lived fission fragments and structural materials.

The n_TOF facility at CERN [4]-a pulsed neutron source coupled to a $200 \mathrm{~m}$ flight path designed to study neutron-nucleus interactions in energy ranges from a few $\mathrm{meV}$ to several $\mathrm{GeV}$ - initiated by Rubbia [5], gives the unique possibility to measure these urgently needed capture and fission cross sections.

Several capture and fission cross-section measurements on various long-lived $\mathrm{U}, \mathrm{Pu}, \mathrm{Np}, \mathrm{Am}$ and $\mathrm{Cm}$ isotopes have already been performed during the two n_TOF measurement campaigns (2001-2004 and 2009-2012), for instance high accuracy results on the radiative capture of ${ }^{232} \mathrm{Th}$ and fission of ${ }^{233} \mathrm{U}$, both of fundamental importance for the development of the Th/U fuel cycle [6-9]. Fission cross-sections were determined with high accuracy also on ${ }^{237} \mathrm{~Np}$ and ${ }^{240} \mathrm{Pu}$ $[10,11]$, two of the minor actinides most abundantly produced in current reactors. Recently, capture cross section of ${ }^{238} \mathrm{U},{ }^{236} \mathrm{U},{ }^{241} \mathrm{Am}$ and fission cross section of ${ }^{240} \mathrm{Pu}$ and ${ }^{242} \mathrm{Pu}$ have been measured with the aim of reaching unprecedented accuracy $[8,12]$. An overview on the $n_{-}$TOF CERN fission program can be found in [13].

Moreover, Experimental Area II or (EAR-2) [14] has been operational from 2014 on with a gain in flux of more than 20 times compared to Experimental Area I (EAR-1), as thus will allow n_TOF to expand its measurement capabilities to even smaller samples of more short-lived and rare isotopes, such as ${ }^{230} \mathrm{Th},{ }^{232} \mathrm{U},{ }^{238} \mathrm{U},{ }^{240} \mathrm{Pu},{ }^{244} \mathrm{Cm}$ and even fission products.

As a consequence of this situation, we observe a strongly increasing demand for rare and exotic radioactive sample material, especially minor actinides and fission products, because a basic ingredient of a reliable cross section determination with a low uncertainty is a high quality target, containing sufficient amount of the desired isotopes and meeting the specific requirements of the measurement. The currently available spent fuel solutions can be a source of such valuable material.

\section{Design of the flow sheet}

The model developed for the conditioning of spent nuclear fuel solutions is shown schematically in Fig. 1. This model consists of Cs-removal, $\mathrm{U}$ and Pu extraction, minor actinides and lanthanides extraction, activation isotopes extraction and final cementation.

The Cs-removal process is the first step for two reasons: (1) the reduction of gamma dose rate on these spent fuel solutions fulfills the requirement of the Fixbox 3 procedure; (2) the risk of radiation-induced decomposition on the extractants used in the following steps is lowered. $\mathrm{U}$ and $\mathrm{Pu}$ extraction is following after the Cs-removal step. The aim of this step is to remove the matrix elements from the spent fuel solutions, which lowers the concentration of interfering ions during extraction of the desired isotopes. As stated in "isotope reclamation", those scientific valuable isotopes (e.g. minor actinides) are in high demand, therefore the extraction of minor actinides as well as the extraction of rare activation isotopes are performed before the cementation procedure. The co-extraction of minor actinides and lanthanides is conducted due to their similar chemical properties [15], and the step of separating minor actinides from lanthanides. For the separation of Am from $\mathrm{Cm}$, currently the separation
Fig. 1 Flow sheet for conditioning of spent nuclear fuel solutions at PSI. MA minor actinides, $L n$ lanthanides

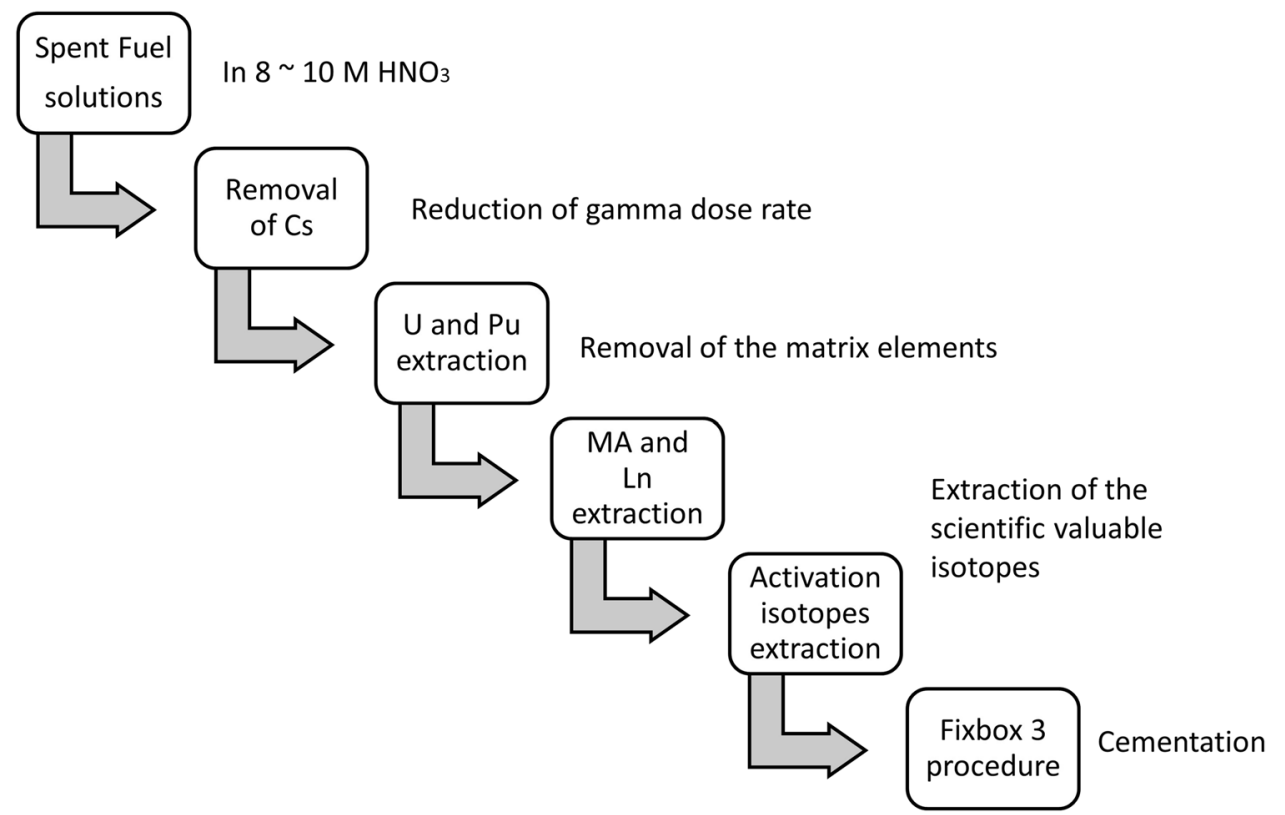


procedure is not determined. This work might be performed properly in the future.

\section{Description of materials in each step}

Because of its operational simplicity, chromatographic separation techniques were evaluated in each separation step presented in the flow sheet.

\section{Cs-removal}

Ammonium molybdophosphate polyacrylonitrile (AMP_ PAN) was used for Cs-removal. This material is an engineered product-immobilized ammonium molybdophosphate (AMP) on polyacrylonitrile (PAN) [16]. It was developed and evaluated by Sebesta et al. [17]. The chemical stability was tested by pre-contacting the AMP_PAN with $1 \mathrm{M} \mathrm{HNO}_{3}$ for a month and the radiation stability of AMP_PAN was tested after receiving $10^{3}-10^{6}$ Gy of either gamma or X-ray dose $[17,18]$. The results of the evaluation on pre-treated AMP_PAN showed that no changes of adsorption properties of AMP_PAN to Cs was observed in comparison with non pre-treated AMP_PAN, which proved the good chemical and radiation stability of AMP_PAN. Later, AMP_PAN was tested at Idaho National Engineering and Environmental Laboratory (INEEL) to remove radioactive $\mathrm{Cs}$ from acidic and radioactive liquid waste. Both batch and column methods experiments with AMP_PAN were performed at INEEL [19-21]. Their results showed that AMP_ PAN has high selectivity to Cs in highly acidic and salt bearing solutions. The evaluation indicated that AMP_PAN is an efficient and promising material to remove Cs from highly acidic solutions. A manuscript concerning the optimization of the chemical separation system for Cs removal has been submitted to the Radiochimica Acta.

\section{$\mathrm{U}$ and Pu extraction}

The liquid-liquid extraction technique as well as the developed extractants have been widely studied for the extraction of $U$ and Pu from spent fuel solutions [22-25]. However, the complexed setup is not suitable for the small-scale extraction task. In this work, the simplified ion-exchange technique and TBP impregnated resin is evaluated for the extraction of $\mathrm{U}$ and $\mathrm{Pu}$. It is an engineered form of $\mathrm{U}$ and Pu selective sorbent material marketed by the company "Triskem" in Europe. This material is produced by immobilizing tributyl-phosphate (TBP) molecules on an inert matrix and it has been studied by Dirks et al. recently [26]. They studied the distribution coefficient $\left(K_{\mathrm{d}}\right)$ of many elements on TBP impregnated resin in a wide range of $\mathrm{HNO}_{3}$ concentrations $(0.1-10 \mathrm{M})$ [26]. Their results indicated that the $K_{\mathrm{d}}$ value of
$\mathrm{U}$ and $\mathrm{Pu}$ increased with the concentration of $\mathrm{HNO}_{3}$, while the $K_{\mathrm{d}}$ value of other elements (mainly fission products) remained small. Details can be found in [27]. This study proved that the TBP impregnated resin has high selectivity for $\mathrm{U}$ and $\mathrm{Pu}$ in concentrated $\mathrm{HNO}_{3}$ solutions. Therefore, TBP impregnated resin is a suitable material to remove the matrix elements of $\mathrm{U}$ and $\mathrm{Pu}$ from these high acidic spent fuel solutions.

\section{Minor actinides and lanthanides extraction}

The minor actinides and lanthanides extraction from spent nuclear fuel solutions have attracted much attention recently and several extractants were developed and tested [28]. In this study, the DGA-resin was tested for the extraction of minor actinides and lanthanides extraction. This material was developed by "Eichrom Technologies Inc." in the US and is marketed by the company "Triskem" in Europe. The DGA-resin is synthesized by immobilizing $N, N, N^{\prime}, N^{\prime}$-tetran-octyldiglycolamide (TODGA) molecules on an inert matrix and it has been studied extensively recently. Pourmand et al. evaluated the distribution coefficient of many elements on the DGA-resin in wide range of $\mathrm{HNO}_{3}$ concentrations (0.1-12 M) [29]. Their results showed that the minor actinides and lanthanides have high affinity to this material in concentrated $\mathrm{HNO}_{3}$, which indicated that the DGA-resin is an effective material to extract minor actinides and lanthanides from these highly acidic spent fuel solutions. Details can be found in [30].

\section{Separation of minor actinides from lanthanides}

The separation of minor actinides from lanthanides is a challenging task due to their similar chemical properties and many studies have been performed by different groups [31-35]. In this work, the separation of minor actinides from the DGA-resin (lanthanides) is performed with hydrophilic bis-triazinyl-pyridine (BTP). Geist and Wilden et al. performed experiments of extraction of Am and Eu by the TODGA system with addition of hydrophilic BTP in aqueous phase [36, 37]. They found that the extraction of Am was effectively suppressed, but the extraction of Eu was only slightly influenced. The separation factor of $\mathrm{Am} / \mathrm{Eu}$ increased with the concentration of hydrophilic BTP. Since the active component of DGA resin is TODGA, the hydrophilic BTP would be an effective material to separate minor actinides from the DGA resin.

\section{Design of the specific flow diagram}

By considering a chromatographic separation system and the selected sorbents, the specific conceptual flow diagram is depicted in Fig. 2 and the selected sorbents are shown 


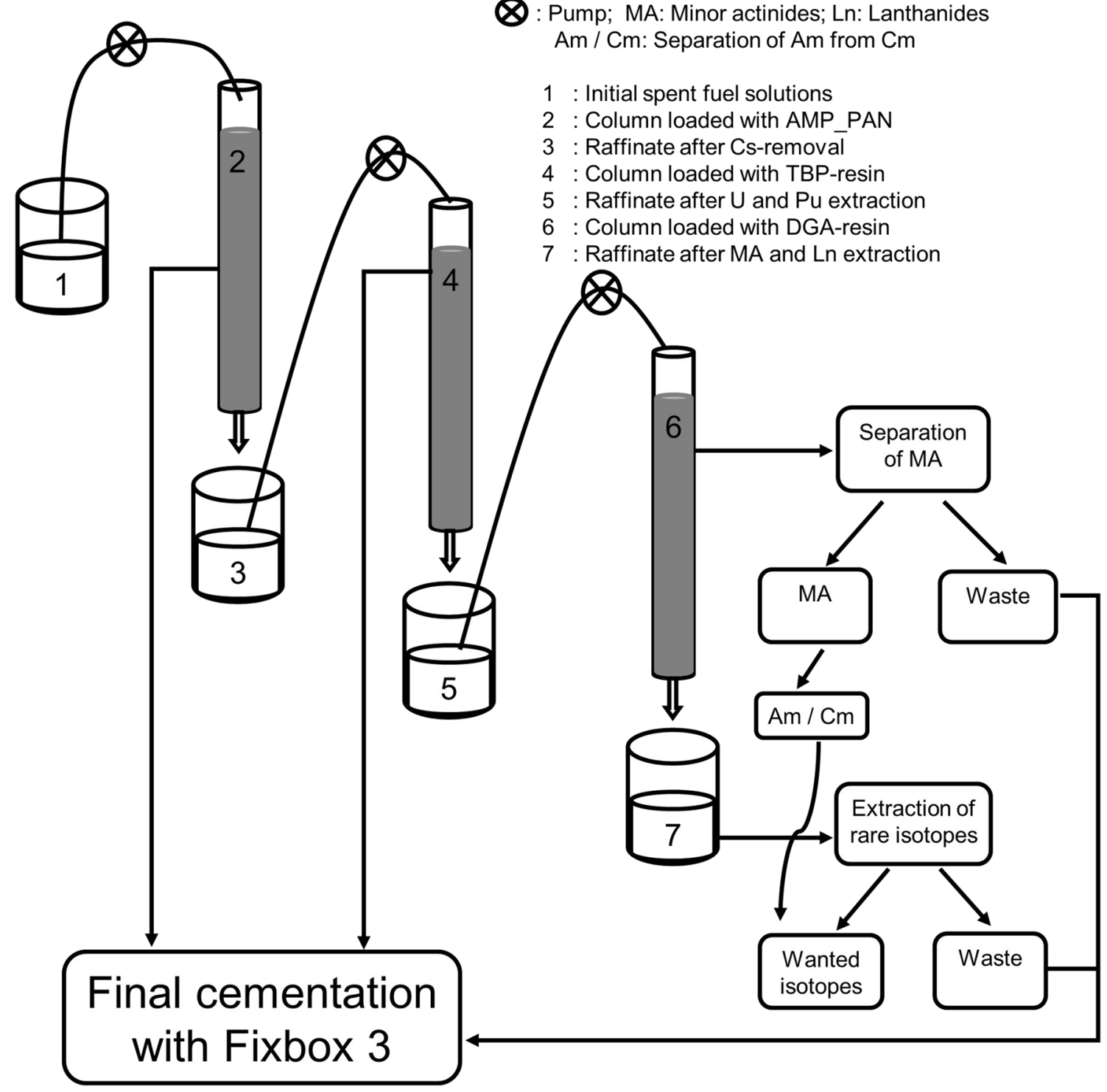

Fig. 2 Specific conceptual flow diagram for the treatment of spent fuel solutions

Table 1 The information of selected materials

\begin{tabular}{lll}
\hline Task & Materials & Source \\
\hline Cs-removal & AMP_PAN & "Triskem" \\
U and Pu extraction & TBP impregnated resin & "Triskem" \\
MA and Ln extraction & DGA resin & "Triskem" \\
MA separation & Hydrophilic BTP & "Sigma-Aldrich" \\
\hline
\end{tabular}

MA minor actinides, $L n$ lanthanides

in Table 1. In the chromatographic separation system, a transparent glass tube was used for loading the sorbent and a Teflon ${ }^{\mathrm{TM}}$ frit was put in the bottom of the tube for holding the sorbent. A peristaltic pump (ISMATEC ${ }^{\circledR}$ ) was used to control the flow rate of the solution though the column and plastic bottles are used for the collection of effluents.

The loaded sorbents (AMP_PAN and TBP-resin) as well as the adsorbates $(\mathrm{Cs}, \mathrm{U}$ and $\mathrm{Pu})$ and the waste produced in each separation step were sent to the Fixbox 3 facility for final cementation. The separated isotopes will be kept for further scientific investigations.

\section{Conclusions and outlook}

In the present paper, a concept for conditioning of spent nuclear fuel solutions at PSI was presented. An already developed facility (Fixbox 3) will be used for the final cementation of these high-level solutions. In order to fulfill 
the requirement of Fixbox 3 and to meet the demand of scientific valuable isotopes, extraction of $\mathrm{Cs}, \mathrm{U}$ and $\mathrm{Pu}$, minor actinides and lanthanides, and rare fission products are included into a designed flow sheet for the disposal of these spent fuel solutions. For the purpose of separation or extraction of the desired elements, chromatographic separation techniques are currently evaluated. Promising materials were selected for each extraction step. AMP_PAN, TBP impregnated resin and DGA resin were selected for the extraction of $\mathrm{Cs}, \mathrm{U}$ and $\mathrm{Pu}$, minor actinides and lanthanides, respectively. The hydrophilic BTP was selected for the separation of minor actinides from DGA resin. A conceptual flow diagram containing these separation steps as well as the sorbents was thus developed.

In the future, the selected sorbents will be individually tested by both batch and column methods. The performed tests will allow determining the optimum condition (e.g. acidity) and parameters (e.g. dimension of column and flow rate) of the devices suitable for our tasks. The device presented in Fig. 2 will be tested using simulated solutions in lieu of real spent fuel solutions and later one with the real spent fuel solutions.

The operation of the device will establish the basis for the safe and efficient disposal of the liquid nuclear waste at PSI stemming from nuclear power plants and, additionally, can help to provide urgently needed radioactive samples for scientific experiments like neutron capture and fission cross section measurements.

Acknowledgements This study was sponsored by Swiss nuclear project "Waste treatment and Isotope Reclamation (WIR)". http://www. swissnuclear.ch/en/research-projects-_content-1-1020.html.

\section{Compliance with ethical standards}

Conflict of interest The authors declare no conflict of interest.

Open Access This article is distributed under the terms of the Creative Commons Attribution 4.0 International License (http://creativeco mmons.org/licenses/by/4.0/), which permits unrestricted use, distribution, and reproduction in any medium, provided you give appropriate credit to the original author(s) and the source, provide a link to the Creative Commons license, and indicate if changes were made.

\section{References}

1. Wildi W, Appel D, Buser M, Dermange F, Eckhardt A, Hufschmied P, Keusen H, Aebersold M (2000) Disposal concepts for radioactive waste. Final Report, Federal office of Energy

2. Bruchertseifer H, Sommer E, Steinemann M, Bart G (1993) "Fixbox"-A new technique for the reliable conditioning of plutonium waste solutions. Annual Report, Paul Scherrer Institute

3. IAEA nuclear data section. https://www-nds.iaea.org/sgnucdat/ c3.htm. Accessed 10 July 2019
4. The Neutron time-of-flight facility at CERN. https://ntof-exp.web. cern.ch/ntof-exp/. Accessed 10 July 2019

5. Rubbia C, Rubio JA, Buono S, Carminati F, Fierier N, Gálvez J, Gelès C, Kadi Y, Klapisch R, Mandrillon P, Revol JPC, Roche C (1995) Conceptual design of a solid neutron operated high power energy amplifier. Report: CERN-AT-95-44-ET

6. Gunsing $\mathrm{F}$ et al (2012) Measurement of resolved resonances of Th-232 (n, gamma) at the n-TOF facility at CERN. Phys Rev C. https://doi.org/10.1103/PhysRevC.85.06460

7. Aerts $\mathrm{G}$ et al (2006) Neutron capture cross section of ${ }^{232} \mathrm{Th}$ measured at the n-TOF facility at CERN in the unresolved resonance region up to $1 \mathrm{MeV}$. Phys Rev C. https://doi.org/10.1103/PhysR evC.73.054610

8. Calviani M et al (2009) High-accuracy ${ }^{235} \mathrm{U}(\mathrm{n}, \mathrm{f})$ cross-section measurement at the white-neutron source n_TOF from nearthermal to $1 \mathrm{MeV}$ neutron energy. Phys Rev C. https://doi. org/10.1103/PhysRevC.80.044604

9. Belloni $\mathrm{F}$ et al (2011) Neutron-induced fission cross-section of ${ }^{233} \mathrm{U}$ in the energy range $0.5<\mathrm{En}<20 \mathrm{MeV}$. Eur Phys J A 47:2. https://doi.org/10.1140/epja/i2011-11002-y

10. Paradela $C$ et al (2010) Neutron-induced fission cross section of ${ }^{234} \mathrm{U}$ and ${ }^{237} \mathrm{~Np}$ measured at the CERN Neutron Time-of-Flight (n_TOF) facility. Phys Rev C. https://doi.org/10.1103/PhysR evC.82.034601

11. Guerrero C et al (2012) Measurement and resonance analysis of the ${ }^{237} \mathrm{~Np}$ neutron capture cross section. Phys Rev C. https://doi. org/10.1103/PhysRevC.85.044616

12. Guerrero $C$ et al (2013) Nuetron capture and fission reactions on 235U: cross sections, $\alpha$-ratios and prompt $\gamma$-ray emission from fission. EPJ Web Conf. https://doi.org/10.1051/epjconf/2013420100 2

13. Tsinganis A et al (2015) The fission programme at the CERN n_TOF facility. Phys Procedia 64:30-139

14. Chiaveri E (2012) Technical Report CERN-INTC-2012-029. INTC-O-015. CERN. Geneva. URL: cds.cern.ch/record/1411635

15. Cotton S (2006) Lanthanide and actinide chemistry. John Wiley \& Sons, Ltd., Chichester

16. Triskem, AMP_PAN product sheet. https://www.triskem-inter national.com/catalog/products/resins-and-accessories/cs-resins/ bl,product,420,0. Accessed 10 July 2019

17. Sebesta F, John J, Motl A, Stamberg K (1995) Evaluation of polyacrylonitrile (PAN) as a binding polymer for absorbers used to treat liquid radioactive wastes. Contractor Report. Sandia National Laboratories. SAND95-2729

18. Sebesta F, John J, Motl A (1996) Phase II report on the evaluation of polyacrylonitrile (PAN) as a binding polymer for absorbers used to treat liquid wastes. Contractor Report. Sandia National Laboratories.SAND96-1088

19. Tranter TJ, Herbst RH, Todd TA, Olson AL, Eldredge HB (2002) Evaluation of ammonium molybdophosphate-polyacrylonitrile (AMP_PAN) as a cesium selective sorbent for the removal of ${ }^{137} \mathrm{Cs}$ from acidic nuclear waste solutions. Adv Environ Res 6:107-121

20. Tranter TJ, Herbst RS, Todd TA (2002) Determination of a solid phase mass transfer coefficient for modeling an adsorption bed system using ammonium molybdophospate-polyacrylonitrile (AMP_PAN) as a sorbent for the removal of ${ }^{137} \mathrm{Cs}$ from acidic nuclear waste solutions. Adsorption 8:291-299

21. Todd TA, Mann NR, Tranter TJ, Sebesta F, John J, Motl A (2002) Cesium sorption from concentrated acidic tank wastes using ammonium molybdophosphate-polyacrylonitrile composite sorbents. J Radioanal Nucl Chem 254:47-52

22. Wang C-Z, Lan J-H, Feng Y-X, Wei Y-Z, Zhao Y-L, Chai Z-F, Shi W-Q (2014) Extraction complexes of Pu(IV) with carbamoylmethylphosphine oxide ligands: a relativistic density functional study. Radiochim Acta 102:77-86 
23. May I, Taylor RJ, Denniss IS, Wallwork AL (1999) Actinide complexation in the purex process. Czech J Phys 49:597-601

24. Uchiyama G, Mineo H, Hotoku S, Asakura T, Kamei K, Watanabe M, Nakano Y, Kimura S, Fujine S (2000) Parc process for an advanced purex process. Prog Nucl Energy 37:151-156

25. Zabunoglu OH, Ozdemir L (2005) Purex co-processing of spent LWR fuels: flow sheet. Ann Nucl Energy 32:151-162

26. Dirks C, Vajda N, Kovács-Széles E, Bombard A, Happel S (2014) Characterization of a TBP resin and development of methods for the separation of actinides and the purification of Sn. Poster presented at the 17th Radiochemistry conference

27. Triskem, TBP resin product sheet. https://www.triskem-internatio nal.com/scripts/files/5c5864aeadddb9.15147490/PS_TBP\%20Res in_EN_160927.pdf. Accessed 10 July 2019

28. Leoncini A, Huskens J, Verboom W (2017) Ligands for f-element extraction used in the nuclear fuel cycle. Chem Soc Rev 46:7229-7273

29. Pourmand A, Dauphas N (2010) Distribution coefficients of 60 elements on TODGA resin: application to Cs, Lu, Hf, $\mathrm{U}$ and $\mathrm{Th}$ isotope geochemistry. Talanta 81(3):741-753

30. Triskem, DGA resin product sheet. https://www.triskem-internatio nal.com/scripts/files/5c585f394367f7.40914978/PS_DGA\%20Res in_EN_151210.pdf. Accessed 10 July 2019

31. Lan J-H, Shi W-Q, Yuan L-Y, Li J, Zhao Y-L, Chai Z-F (2012) Recent advances in computational modeling and simulations on the An (III)/Ln (III) separation process. Coord Chem Rev 256:1406-1417

32. Kong X-H, Qun-Yan W, Lan J-H, Wang C-Z, Chai Z-F, Nie C-M, Shi W-Q (2018) Theoretical insights into preorganized pyridylpyrazole-based ligands toward the separation of Am(III)/ Eu(III). Inorg Chem 57:14810-14820

33. Huang P-W, Wang C-Z, Qun-Yan W, Lan J-H, Song G, Chai Z-F, Shi W-Q (2018) Uncovering the impact of 'capsule' shaped amine-type ligands on $\mathrm{Am}(\mathrm{III}) / \mathrm{Eu}$ (III) separation. Phys Chem Chem Phys 20:1030-1038

34. Matsumura T, Takeshita K (2008) Extraction separation of trivalent minor actinides from lanthanides with hydrophobic derivatives of TPEN. Prog Nucl Energy 50:470-475

35. Hill C, Madic C, Baron P, Ozawa M, Tanaka Y (1998) Trivalent minor actinides/lanthanides separation, using organophosphinic acids. J Alloys Compd 271:159-162

36. Geist A, Müllich U, Magnusson D, Kaden P, Modolo G, Wilden A, Zevaco T (2012) Actinide (III)/Lanthanide (III) separation via selective aqueous complexation of actinides (III) using a hydrophilic 2,6-bis(1,2,4-triazin-3-yl)-pyridine in nitric acid. Solvent Extr Ion Exch 30:433-444

37. Wilden A, Modolo G, Sypula M, Geist A, Magnusson D (2012) The recovery of An(III) in an innovative-sanex process using a todga-based solvent and selective stripping with a hydrophilic BTP. Procedia Chem 7:418-424

Publisher's Note Springer Nature remains neutral with regard to jurisdictional claims in published maps and institutional affiliations. 